\title{
Safety and Efficacy of Sirolimus- and Paclitaxel-Eluting Coronary Stents
}

\author{
Gregg W. Stone, M.D., Jeffrey W. Moses, M.D., Stephen G. Ellis, M.D., \\ Joachim Schofer, M.D., Keith D. Dawkins, M.D., Marie-Claude Morice, M.D., \\ Antonio Colombo, M.D., Erick Schampaert, M.D., Eberhard Grube, M.D., \\ Ajay J. Kirtane, M.D., Donald E. Cutlip, M.D., Martin Fahy, M.Sc., \\ Stuart J. Pocock, Ph.D., Roxana Mehran, M.D., and Martin B. Leon, M.D.
}

\section{ABSTRACT}

From Columbia University Medical Center and the Cardiovascular Research Foundation, New York (G.W.S., J.W.M., A.J.K., M.F., R.M., M.B.L.); Cleveland Clinic, Cleveland (S.G.E.); Hamburg University Cardiovascular Center, Hamburg, Germany (J.S.); Southampton University Hospital, Southampton, United Kingdom (K.D.D.); Institut Cardiovasculaire Paris Sud, Massy, France (M.-C.M.); San Raffaele Hospital, Milan (A.C.); Hôpital du Sacre-Coeur de Montréal, Montreal (E.S.); Heart Center Siegburg, Siegburg, Germany (E.G.); Harvard Clinical Research Institute, Boston (D.E.C.); and the London School of Hygiene and Tropical Medicine, London (S.J.P.). Address reprint requests to $\mathrm{Dr}$. Stone at Columbia University Medical Center, Cardiovascular Research Foundation, 111 E. 59th St., 11th Fl., New York, NY 10022 , or atgs2184@columbia.edu.

This article (10.1056/NEJMoa067193) was published at www.nejm.org on February 12, 2007.

N EnglJ Med 2007;356:998-1008. Copyright (c) 2007 Massachusetts Medical Society.

\section{BACKGROUND}

The safety of drug-eluting stents has been called into question by recent reports of increased stent thrombosis, myocardial infarction, and death. Such studies have been inconclusive because of their insufficient size, the use of historical controls, a limited duration of follow-up, and a lack of access to original source data.

\section{METHODS}

We performed a pooled analysis of data from four double-blind trials in which 1748 patients were randomly assigned to receive either sirolimus-eluting stents or baremetal stents and five double-blind trials in which 3513 patients were randomly assigned to receive either paclitaxel-eluting stents or bare-metal stents; we then analyzed the major clinical end points of the trials.

\section{RESULTS}

The 4-year rates of stent thrombosis were $1.2 \%$ in the sirolimus-stent group versus $0.6 \%$ in the bare-metal-stent group $(\mathrm{P}=0.20)$ and $1.3 \%$ in the paclitaxel-stent group versus $0.9 \%$ in the bare-metal-stent group $(\mathrm{P}=0.30)$. However, after 1 year, there were five episodes of stent thrombosis in patients with sirolimus-eluting stents versus none in patients with bare-metal stents $(\mathrm{P}=0.025)$ and nine episodes in patients with paclitaxel-eluting stents versus two in patients with bare-metal stents $(\mathrm{P}=0.028)$. The 4-year rates of target-lesion revascularization were markedly reduced in both the sirolimus-stent group and the paclitaxel-stent group, as compared with the bare-metal-stent groups. The rates of death or myocardial infarction did not differ significantly between the groups with drug-eluting stents and those with bare-metal stents.

\section{CONCLUSIONS}

Stent thrombosis after 1 year was more common with both sirolimus-eluting stents and paclitaxel-eluting stents than with bare-metal stents. Both drug-eluting stents were associated with a marked reduction in target-lesion revascularization. There were no significant differences in the cumulative rates of death or myocardial infarction at 4 years. 
Y REDUCING NEOINTIMAL HYPERPLASIA after vascular injury, drug-eluting coronaryartery stents decrease late luminal loss (the difference between the minimal luminal diameter immediately after the procedure and the diameter at 6 months) and angiographic restenosis, as compared with bare-metal stents. This decrease, in turn, reduces the need for subsequent revascularization procedures. ${ }^{1-9}$ Despite these benefits, drug-eluting stents may engender adverse arterial responses, including delayed endothelialization and hypersensitivity to the polymeric coating that regulates drug dose and release kinetics. ${ }^{10-13} \mathrm{Re}-$ cent reports from randomized trials and observational studies using historical controls have suggested that drug-eluting stents may be associated with increased rates of late stent thrombosis and death, as compared with bare-metal stents. ${ }^{14-17}$ These studies have been inconclusive, however, because of an insufficient number of patients, the absence of concurrent controls, a limited duration of follow-up, and a lack of access to original source data. Since more than 1 million of these permanent bioactive devices are implanted in patients annually, understanding the relative safety and efficacy of drug-eluting stents represents a major public health imperative.

To address the limitations of previous studies, we performed a pooled analysis of data from four double-blind trials in which patients were randomly assigned to receive polymer-based sirolimus-eluting stents or bare-metal stents and five double-blind trials in which patients were randomly assigned to receive polymer-based paclitaxel-eluting stents or bare-metal stents. We report on the safety and efficacy of drug-eluting stents with 4-year follow-up after device implantation.

\section{METHODS}

\section{STUDY DESCRIPTION}

The databases from four prospective, multicenter, double-blind, placebo-controlled randomized trials of sirolimus-eluting stents versus bare-metal stents were obtained from Cordis. These trials were the Randomized Study with the Sirolimus-Coated Bx Velocity Balloon-Expandable Stent in the Treatment of Patients with De Novo Native Coronary-Artery Lesions (RAVEL), the Sirolimus-Eluting Balloon-Expandable Stent in the Treatment of Patients with De Novo Native Coronary-Artery Lesions (SIRIUS), and the smaller European and Lat- in American (E-SIRIUS) and Canadian (C-SIRIUS) trials. ${ }^{1-4}$ Similarly, the databases from five prospective, multicenter, double-blind, placebo-controlled, randomized trials of paclitaxel-eluting stents versus bare-metal stents were obtained from Boston Scientific. These trials consisted of the studies TAXUS-I, TAXUS-II, TAXUS-IV, TAXUS-V, and TAXUS-VI. ${ }^{5-9}$ These specific trials were selected because they are the only double-blind trials that compared each of the drug-eluting stents with bare-metal controls and that also served as the basis for the approval of the drug-eluting stents in the United States and Europe. In both cases, permission was obtained for the performance of an unrestricted, patient-level pooled analysis.

Details of the design and conduct of each of the trials included in these analyses have been reported previously. ${ }^{1-9}$ In each trial, patients with a single previously untreated native coronary-artery lesion were prospectively and randomly assigned in equal proportion to receive either a drug-eluting stent or an otherwise equivalent bare-metal stent. Entry criteria, device specifications, and geographic location varied somewhat, as outlined in Table 1. At the time of this report, the patients, investigators, study personnel, and sponsors were still unaware of assignments to study groups, with follow-up continuing to 5 years. Data regarding the use of aspirin and a thienopyridine were not consistently captured during follow-up. However, data on the use of antiplatelet drugs at the time of late thrombosis associated with drug-eluting stents were obtained from the manufacturers of both drug-eluting stents. No agreements with the sponsors regarding data confidentiality exist.

\section{END POINTS AND DEFINITIONS}

The goals of our study were to determine the short-term and long-term safety and efficacy of drug-eluting stents as compared with bare-metal stents. Before receiving the study databases, we specified that we would examine the following end points: stent thrombosis, as defined in the study protocols (see the Supplementary Appendix, available with the full text of this article at WwW.nejm.org) ${ }^{1-9}$; revascularization of the target lesion or target vessel; any myocardial infarction and Q-wave and non-Q-wave myocardial infarction; death from any cause and from cardiac and noncardiac causes; composite death or myocardial infarction; composite death or Q-wave myocardial infarction; and composite death from car- 


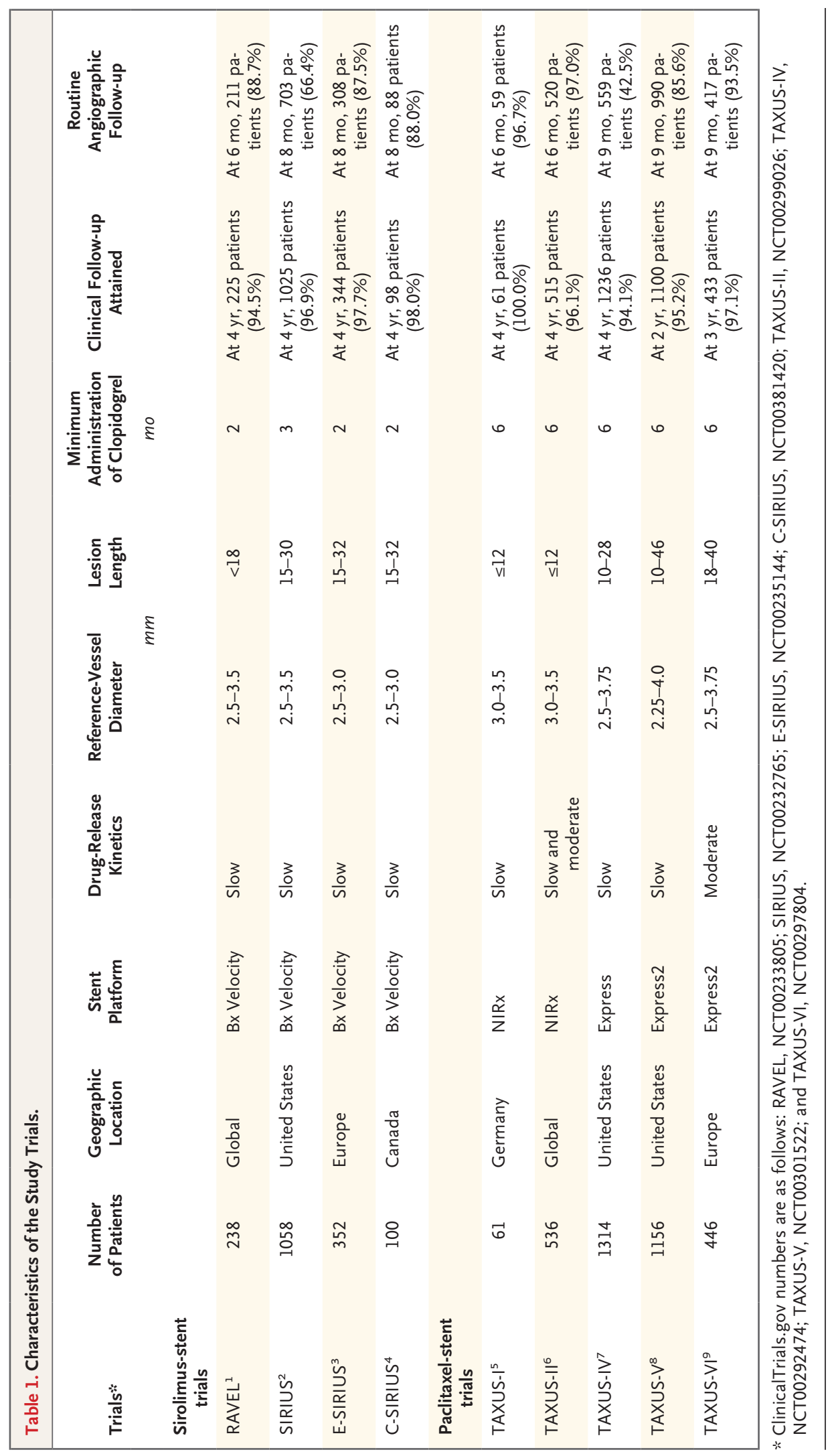


diac causes or myocardial infarction. The following time periods were prespecified for analysis of event rates: the time from stent implantation until 30 days after implantation, from 30 days after implantation until the latest follow-up, from 30 days after implantation until 1 year, from 1 year after implantation until the latest follow-up, and from the time of stent implantation until the latest follow-up.

We used data from the original databases, as defined and adjudicated by the clinical events committees for each study, in our analysis. ${ }^{1-9}$ Since the individual adverse-event narratives and original source documents were not available to us, readjudication of individual events to accommodate common definitions was not possible.

\section{STATISTICAL ANALYSIS}

We compared categorical variables by the chisquare test or Fisher's exact test. Continuous variables are described as means ( \pm SD) and were compared by means of unpaired t-tests. At the time of this report, we had access to 5 -year data from RAVEL and TAXUS-I; 4-year data from SIRIUS, E-SIRIUS, C-SIRIUS, TAXUS-II, and TAXUS-IV; 3-year data from TAXUS-VI; and 2-year data from TAXUS-V. We used Kaplan-Meier time-to-event estimates for the primary analyses, which were compared with the log-rank or exact log-rank test. Analyses were truncated at 4 years of follow-up owing to the small number of patients with data thereafter. We included data from all patients that were analyzed in each of the original study reports in our analysis, with follow-up data censored at the time of first event (for each specific event curve) or latest known follow-up. The Breslow-Day test for heterogeneity demonstrated that trials involving sirolimus-eluting stents and paclitaxel-eluting stents were sufficiently homogeneous to justify the pooled analyses performed. All P values are twosided.

\section{RESULTS}

\section{PATIENTS}

A total of 1748 patients were randomly assigned to study groups and underwent percutaneous coronary intervention in the RAVEL and three SIRIUS trials comparing sirolimus-eluting stents with bare-metal stents (the sirolimus-stent trials). Another 3513 patients were randomly assigned to study groups and underwent percutaneous coro- nary intervention in the five TAXUS trials comparing paclitaxel-eluting stents with bare-metal stents (the paclitaxel-stent trials). The baseline demographic, procedural, and angiographic characteristics of the patients were well matched in both sets of trials (Table 2), except that in the sirolimusstent trials, diabetes was slightly more prevalent among patients who received bare-metal stents than among those who received sirolimus-eluting stents. The lengths of lesions and total implanted stents were both greater in the paclitaxel-stent trials than in the sirolimus-stent trials (reflecting varying criteria for trial entry), although more stents per patient were used in the sirolimusstent trials. Baseline reference measures of vessel diameter and lesion severity were similar for stenoses treated with both types of drug-eluting stents and for those treated with bare-metal stents.

\section{STENT THROMBOSIS}

From stent implantation through 4-year followup, the rates of stent thrombosis among patients with sirolimus-eluting stents did not differ significantly from those with bare-metal stents $(1.2 \%$ and $0.6 \%$, respectively; $\mathrm{P}=0.20$ ) (Table 3 and Fig. 1 and 2). Similarly, there were no significant differences in the 4-year cumulative rates of stent thrombosis between patients with paclitaxel-eluting stents and those with bare-metal stents $(1.3 \%$ and $0.9 \%$, respectively; $\mathrm{P}=0.30$ ). However, between 1 and 4 years, the rates of stent thrombosis in the sirolimus-stent group and the bare-metal-stent group were $0.6 \%$ versus none $(\mathrm{P}=0.025$, consistent with one extra event per 489 patient-years); during the same period, the rates in the paclitaxelstent group and the bare-metal-stent group were $0.7 \%$ versus $0.2 \%(\mathrm{P}=0.028$, consistent with one extra event per 557 patient-years). After 1 year, of the five patients who had late thrombosis associated with sirolimus-eluting stents, two patients were taking aspirin and clopidogrel, two were taking only aspirin, and one was taking no antiplatelet agent. Of the nine patients with late thrombosis associated with paclitaxel-eluting stents, three were taking only aspirin, and five were taking no antiplatelet agent; the status of one patient is unknown.

\section{REVASCULARIZATION}

Both drug-eluting stents markedly reduced the rates of target-lesion revascularization and tar- 


\begin{tabular}{|c|c|c|c|c|c|c|}
\hline Variable & $\begin{array}{c}\text { Sirolimus-Eluting } \\
\text { Stent }\end{array}$ & Bare-Metal Stent & P Value & $\begin{array}{l}\text { Paclitaxel-Eluting } \\
\text { Stent }\end{array}$ & Bare-Metal Stent & P Value \\
\hline Age $-y r$ & $61.9 \pm 11.1$ & $61.9 \pm 10.7$ & 0.91 & $62.4 \pm 10.8$ & $62.2 \pm 10.6$ & 0.49 \\
\hline Male sex - no./total no. (\%) & $629 / 878(71.6)$ & $622 / 870(71.5)$ & 0.96 & $1271 / 1755(72.4)$ & $1278 / 1758(72.7)$ & 0.88 \\
\hline \multicolumn{7}{|l|}{ Diabetes — no./total no. (\%) } \\
\hline Any type & $195 / 878(22.2)$ & $233 / 868(26.8)$ & 0.03 & $408 / 1755(23.2)$ & $419 / 1758(23.8)$ & 0.69 \\
\hline Requiring insulin & $51 / 878(5.8)$ & $62 / 868(7.1)$ & 0.28 & $127 / 1729(7.3)$ & $138 / 1730(8.0)$ & 0.52 \\
\hline $\begin{array}{l}\text { Hypertension - no./total } \\
\text { no. (\%) }\end{array}$ & $557 / 873(63.8)$ & $548 / 866(63.3)$ & 0.84 & $1217 / 1755$ (69.3) & $1191 / 1754$ (67.9) & 0.36 \\
\hline $\begin{array}{l}\text { Hyperlipidemia - no./total } \\
\text { no. (\%) }\end{array}$ & $613 / 866(70.8)$ & $617 / 859(71.8)$ & 0.67 & $1230 / 1744(70.5)$ & $1237 / 1751(70.6)$ & 0.94 \\
\hline $\begin{array}{l}\text { Current smoker - no./ } \\
\text { total no. (\%) }\end{array}$ & $183 / 862(21.2)$ & $210 / 858(24.5)$ & 0.12 & $413 / 1742(23.7)$ & $401 / 1749$ (22.9) & 0.60 \\
\hline \multicolumn{7}{|l|}{$\begin{array}{r}\text { Target coronary artery - } \\
\text { no./total no. (\%) }\end{array}$} \\
\hline Left anterior descending & $408 / 875(46.6)$ & $407 / 872(46.7)$ & 1.00 & $733 / 1744(42.0)$ & 730/1752 (41.7) & 0.84 \\
\hline Left circumflex & $181 / 875(20.7)$ & $181 / 872(20.8)$ & 1.00 & $444 / 1744(25.5)$ & 419/1752 (23.9) & 0.31 \\
\hline Right coronary & $254 / 875(29.0)$ & $254 / 872(29.1)$ & 1.00 & $560 / 1744(32.1)$ & $592 / 1752(33.8)$ & 0.30 \\
\hline Left main coronary & $3 / 875(0.3)$ & $3 / 872(0.3)$ & 1.00 & NA & NA & NA \\
\hline Saphenous-vein graft & $0 / 875$ & $1 / 872(<0.1)$ & 0.50 & NA & NA & NA \\
\hline $\begin{array}{l}\text { Reference vessel diameter - } \\
\mathrm{mm}\end{array}$ & $2.72 \pm 0.45$ & $2.72 \pm 0.48$ & 0.98 & $2.74 \pm 0.51$ & $2.74 \pm 0.51$ & 0.83 \\
\hline $\begin{array}{l}\text { Minimal luminal diameter - } \\
\mathrm{mm}\end{array}$ & $0.94 \pm 0.37$ & $0.93 \pm 0.36$ & 0.50 & $0.91 \pm 0.35$ & $0.91 \pm 0.37$ & 0.58 \\
\hline Diameter stenosis — \% & $65.2 \pm 11.9$ & $65.7 \pm 11.6$ & 0.47 & $67.0 \pm 10.9$ & $66.8 \pm 11.5$ & 0.59 \\
\hline Lesion length $-\mathrm{mm}$ & $13.8 \pm 5.7$ & $13.9 \pm 5.9$ & 0.96 & $15.1 \pm 7.9$ & $15.1 \pm 8.0$ & 0.88 \\
\hline No. of stents & $1.42 \pm 0.69$ & $1.39 \pm 0.61$ & 0.38 & $1.21 \pm 0.48$ & $1.19 \pm 0.46$ & 0.19 \\
\hline Total stent length $-\mathrm{mm}$ & $22.9 \pm 9.0$ & $22.5 \pm 8.1$ & 0.31 & $24.4 \pm 11.2$ & $24.1 \pm 11.1$ & 0.45 \\
\hline
\end{tabular}

* Plus-minus values are means \pm SD. NA denotes not applicable.

get-vessel revascularization at 4 years (Table 3). The difference in the rates of clinical restenosis peaked at approximately 1 year and then remained stable through 4 years of follow-up (Fig. 1 and 2). In the cohort of patients undergoing routine angiographic follow-up, both drug-eluting stents greatly reduced late luminal loss and binary restenosis, as compared with bare-metal stents, both in-stent (within the stent margins) and in-segment (in-stent plus $5 \mathrm{~mm}$ proximal and distal margins) (see the Supplementary Appendix for details).

\section{DEATH AND MYOCARDIAL INFARCTION}

The cumulative 4-year rate of death from any cause in the sirolimus-stent group did not differ significantly from that in the bare-metal-stent group $(6.7 \%$ vs. $5.3 \%, P=0.23)$; the difference in rates between the paclitaxel-stent group and the bare-metal-stent group was also not significant (6.1\% vs. $6.6 \%, \mathrm{P}=0.68$ ) (Table 3 and Fig. 1 and 2). Cumulative rates of death from any cause and from cardiac and noncardiac causes were also similar in both drug-eluting-stent groups and the bare-metal-stent group at 4 years (Table 3) and during each prespecified interval (Supplementary Appendix).

The cumulative 4-year rates of myocardial infarction were similar in the sirolimus-stent group and the bare-metal-stent group $(6.4 \%$ vs. $6.2 \%$, $\mathrm{P}=0.86)$ and in the paclitaxel-stent group and the bare-metal-stent group $(7.0 \%$ vs. $6.3 \%, P=$ 0.66 ), with no significant differences in the rates of Q-wave or non-Q-wave myocardial infarction (Table 3 and Fig. 1 and 2). The rates of myocardial infarction were also similar in both drug- 


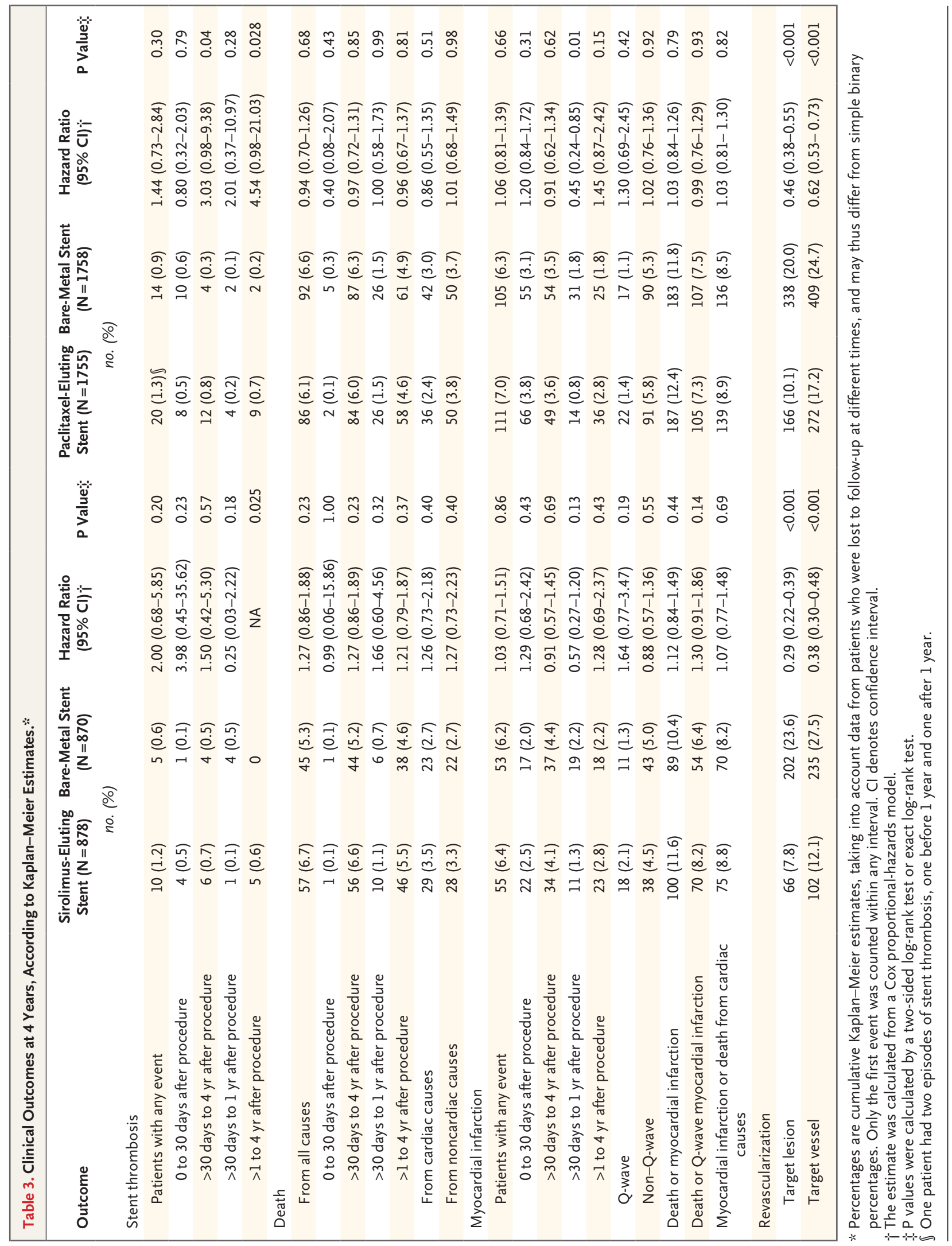




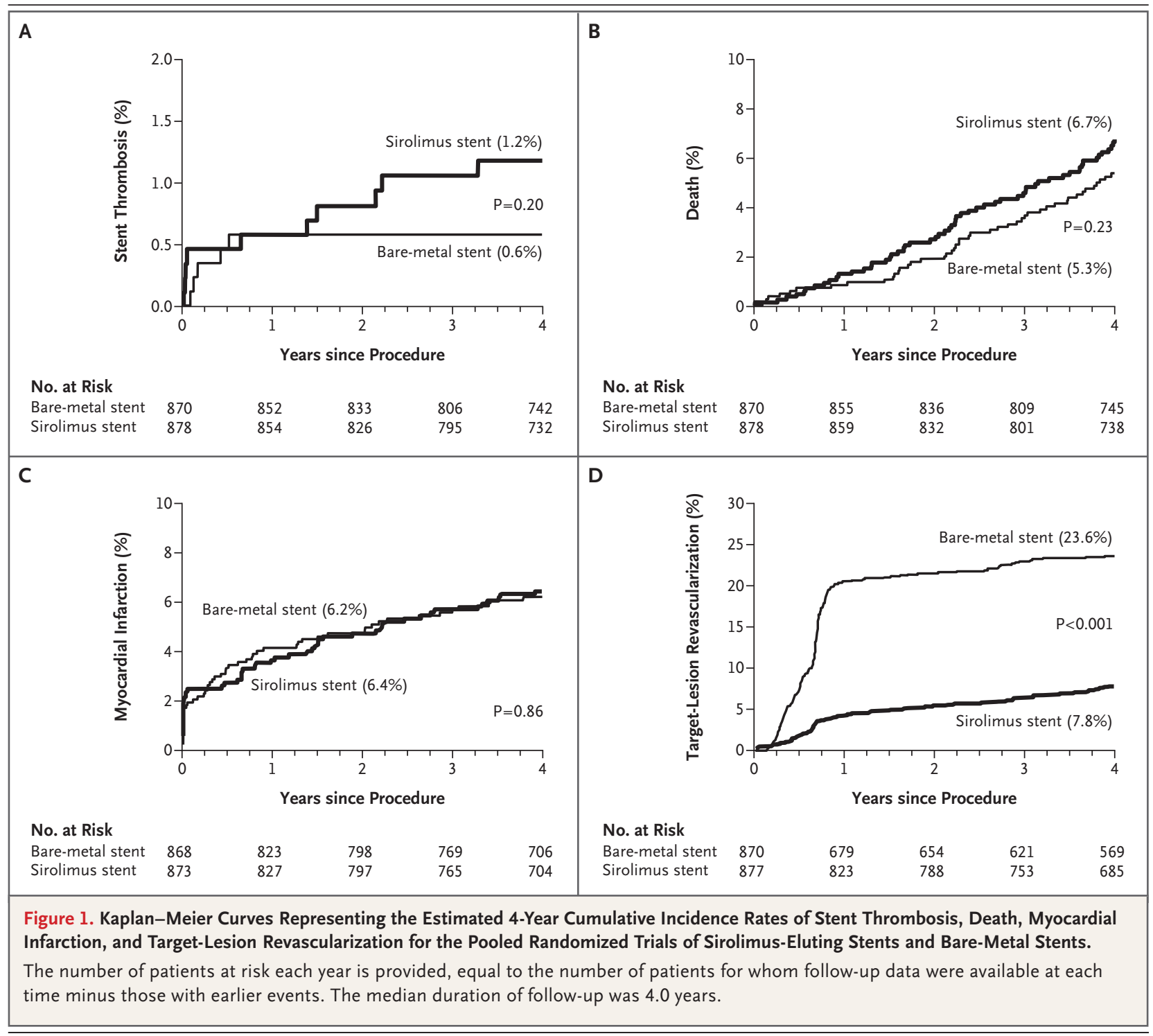

eluting-stent groups and bare-metal-stent group at all prespecified time periods, except that there were significantly fewer myocardial infarctions in the paclitaxel-stent group than in the baremetal-stent group between 30 days after implantation and 1 year $(0.8 \%$ vs. $1.8 \%, \mathrm{P}=0.01)$.

There were no differences in the 4-year composite rates of death or myocardial infarction, death or Q-wave myocardial infarction, or myocardial infarction or death from cardiac causes between either drug-eluting stent and its control (Table 3) or at any interval time period (Supplementary Appendix), except that between 30 days after implantation and 1 year, the composite rate of myocardial infarction or death from cardiac causes was lower in the paclitaxel-stent group than in the bare-metal-stent group (1.4\% vs. $2.5 \%$, $\mathrm{P}=0.03$ ). This reduction in rate was driven by a lower rate of non-Q-wave myocardial infarction in the paclitaxel-stent group than in the baremetal-stent group $(0.4 \%$ vs. $1.6 \%, \mathrm{P}<0.001)$.

\section{DISCUSSION}

We performed a patient-level pooled meta-analysis of four randomized, double-blind trials of sirolimus-eluting stents versus bare-metal stents and five randomized, double-blind trials of paclitaxeleluting stents versus bare-metal stents in single, previously untreated coronary lesions through 


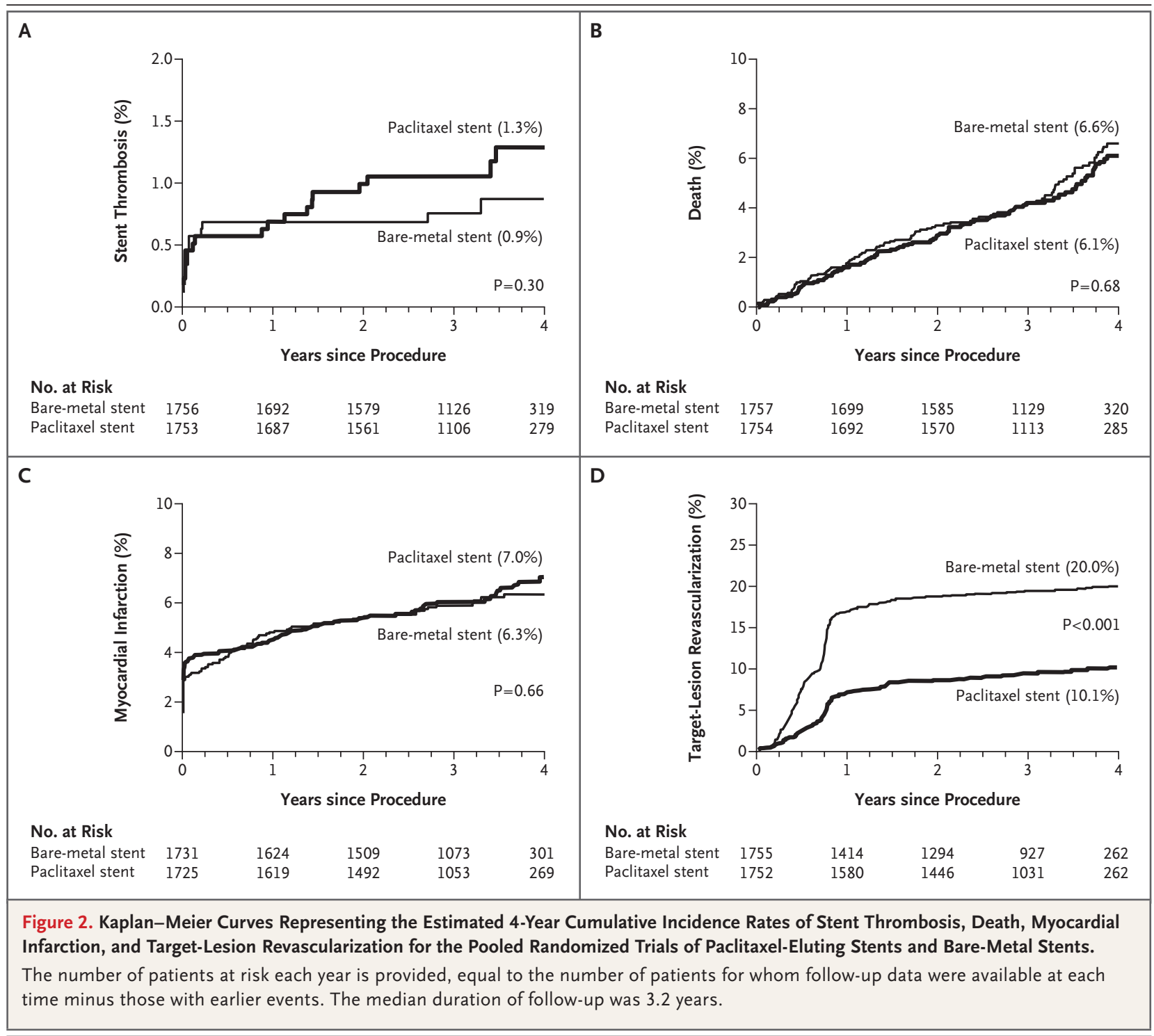

4 years of follow-up. The principal findings were that although the overall rates of stent thrombosis were not significantly increased with drugeluting stents, both sirolimus-eluting stents and paclitaxel-eluting stents were associated with a small but significant increase in the incidence of late stent thrombosis between 1 and 4 years after implantation. In addition, both drug-eluting stents were associated with marked reductions in ischemic target-lesion revascularization and target-vessel revascularization, an advantage that was maintained through 4 years of follow-up. The rates of death or myocardial infarction were not significantly different between the groups with drug-eluting stents and the control groups, ei- ther at 4 years of follow-up or between 1 and 4 years.

The number of episodes of stent thrombosis within the first year were identical among patients with sirolimus-eluting stents and those with bare-metal stents (5 patients with episodes in each group) and among patients with paclitaxel-eluting stents and those with bare-metal stents (12 patients in each group). Between 1 and 4 years, however, there were modest increases in stent thrombosis in both groups with drug-eluting stents, as compared with the control groups (14 patients with episodes in the groups with drugeluting stents vs. 2 patients in the bare-metalstent groups - a finding that is consistent with 
approximately one extra stent thrombosis per 500 patient-years of treatment with drug-eluting stents). Although our study does not identify the potential causes of late stent thrombosis, possible causes include delayed or incomplete endothelialization, late polymer reactions, strut fractures, positive remodeling with stent malapposition with or without aneurysm formation, and new plaque rupture either adjacent to or within the stented site, among others. ${ }^{10-13,18,19}$

Our study also demonstrates a marked and persistent reduction in target-lesion revascularization and target-vessel revascularization with both drug-eluting stents, as compared with baremetal stents. The maximal difference between drug-eluting stents and bare-metal stents in clinical restenosis occurred by 1 year, with the hazard curves remaining parallel between 1 and 4 years. In this regard, the durability of clinical efficacy for drug-eluting stents during late follow-up stands in contradistinction to the "catch-up" phenomenon of late restenosis noted after coronary brachytherapy. ${ }^{20,21}$ Although the performance of routine angiographic follow-up may have increased the absolute difference in the rates of clinical restenosis between drug-eluting stents and bare-metal stents, the relative benefit is unlikely to have been affected. ${ }^{22}$

No significant differences in the cumulative 4-year rates of death or myocardial infarction were observed between patients receiving either drugeluting stents or bare-metal stents. It is possible that reductions in the rates of death or myocardial infarction that otherwise might result from prevention of restenosis by drug-eluting stents may be offset by adverse events resulting from late stent thrombosis. In-stent restenosis presents as acute myocardial infarction in 3.5 to $19.4 \%$ of patients ${ }^{23-26}$ and as such is not always a benign process. However, the majority of episodes of stent thrombosis present as death or myocardial infarction. ${ }^{27,28}$ Thus, a large reduction in a phenomenon with moderate clinical risk (restenosis) may be offset by a small increase in a phenomenon with high clinical risk (stent thrombosis).

It is important to note that stent thromboses occurring subsequent to any target-lesion revascularization were excluded from the counts of episodes of stent thrombosis in most of the trials (see the definitions of stent thrombosis in the Supplementary Appendix). ${ }^{29}$ The purpose of this exclusion was to ensure that only episodes of stent thrombosis related to the original stent were included. However, the procedures to treat restenosis (balloon angioplasty, brachytherapy, or additional stenting) may result in "secondary" episodes of stent thrombosis. Such secondary stent thromboses would be expected to be more common with bare-metal stents, since revascularization procedures are much more common with these stents. Indeed, in an unpublished analysis, when such secondary episodes were considered, no overall or late differences in the patient-level rates of stent thrombosis between drug-eluting stents and bare-metal stents were present. ${ }^{29}$ Since data regarding death and myocardial infarction were not censored after target-lesion revascularization, greater rates of restenosis and secondary thrombosis with bare-metal stents than with drugeluting stents probably contributed to the similar observed overall rates of death and myocardial infarction between the stent types in our analysis. Given the difficulties in defining stent thrombosis in the absence of angiographic confirmation or results on autopsy, greater emphasis should be placed on the occurrence of death and myocardial infarction, in our opinion, rather than on stent thrombosis, as indicative of the overall safety profile of a coronary intervention. Moreover, given the observation that the directional effect of drug-eluting stents on subsequent stent thrombosis, revascularization, death, and myocardial infarction may vary, we believe that composite measures combining safety and efficacy end points should be avoided in future trials of antirestenotic devices.

Our findings differ from those of some other investigators, who have suggested, on the basis of trial-level meta-analyses, that overall rates of stent thrombosis and death are higher with drugeluting stents than with bare-metal stents. ${ }^{16,17}$ These discrepancies may be partially explained by the fact that we had access to the complete patient-level data from the trials we examined and did not have to rely on an estimation of event rates from limited published results, abstracts, and online summaries. We also confined our analysis to a precisely defined subgroup of clinical trials involving drug-eluting stents, whereas some previous analyses have also included later studies that were not double-blind. ${ }^{16}$

Several limitations of our analysis deserve comment. First, given the relatively infrequent occurrence of death, myocardial infarction, and stent thrombosis, larger studies with longer-term fol- 
low-up are required to detect small differences in event rates. Moreover, we made no adjustments for the multiple end points examined. The interval data analyses in particular should be considered hypothesis-generating. Second, our analysis is most applicable for patients with single, previously untreated coronary lesions, as reflected in the labels for sirolimus-eluting stents (lesions as long as $30 \mathrm{~mm}$ in vessels of 2.5 to $3.5 \mathrm{~mm}$ in diameter) and paclitaxel-eluting stents (lesions as long as $28 \mathrm{~mm}$ in vessels of 2.5 to $3.75 \mathrm{~mm}$ in diameter) that were approved by the Food and Drug Administration. The rates of stent thrombosis and the relative risk-benefit ratio of drugeluting stents versus bare-metal stents may vary in the "real world," in which stents are implanted in more complex scenarios (i.e., "off-label" use). 27,28 Third, the nine studies we analyzed used different clinical sites, adjudication committees, and core laboratories, with possible differences in definitions and processes. Fourth, the paclitaxelstent trials included both the commercial slow rate-release formulation and the noncommercialized moderate rate-release formulation. However, the results were directionally similar with both devices, and no major differences have been described between the two versions of this stent. ${ }^{6}$ Fifth, in five of the trials, the protocol-specified definitions of stent thrombosis after 30 days required angiographic confirmation and may therefore underestimate the true event rate. Sixth, pooling of the data from sirolimus-stent trials and paclitaxel-stent trials was avoided, since the mechanisms underlying the safety and efficacy of these two types of stents may differ. Given the different entry criteria for types of lesions in the two groups of trials, as well as the different baremetal stents used as controls, comparisons across the two pooled meta-analyses may not be valid. Finally, detailed data regarding the use of antiplatelet medication throughout the follow-up period were not available, precluding firm recom- mendations regarding the optimal duration of thienopyridine administration.

In conclusion, our study examined the relative safety and efficacy of drug-eluting stents, as compared with bare-metal stents, in a pooled, patientlevel analysis of double-blind, randomized trial data. The use of both sirolimus-eluting stents and paclitaxel-eluting stents was associated with a small but significant increase in the incidence of late stent thrombosis between 1 and 4 years after implantation, as compared with that of bare-metal stents. We also reconfirmed the marked benefit of both types of drug-eluting stents in reducing the need for subsequent revascularization procedures, with persistence of this benefit through 4 years of follow-up. We found no significant differences between drug-eluting stents and baremetal stents in the rates of death or myocardial infarction.

Supported by the Cardiovascular Research Foundation.

Dr. Stone reports receiving consulting fees from Boston Scientific, Abbott, Guidant, Xtent, and BMS Imaging, receiving lecture fees from Boston Scientific, Abbott, and Medtronic, having equity interests in Devax and Xtent, and being a member of the board of directors of Devax; Dr. Moses, receiving consulting fees from Cordis; Dr. Ellis, receiving consulting fees from Boston Scientific and Cordis; Dr. Dawkins, receiving consulting fees from Boston Scientific, Abbott, Conor, and Nycomed, receiving lecture fees from Eli Lilly, and receiving research grant support from Boston Scientific; Dr. Schampaert, receiving consulting fees, lectures fees, and research grant support from Boston Scientific and Cordis and receiving lecture fees from Sanofi-Aventis; Dr. Pocock, receiving consulting fees from Boston Scientific and Conor and receiving research grant support from Boston Scientific; Dr. Mehran, receiving research grant support from Boston Scientific, the Medicines Co., Cordis, and Conor; and Dr. Leon, receiving consulting fees from Cordis, Medtronic, Boston Scientific, and OrbusNeich and having equity interests in Conor, Medinol, and OrbusNeich. Drs. Stone, Moses, Kirtane, Mehran, and Leon report that they are directors of the Cardiovascular Research Foundation, a public charity affiliated with Columbia University Medical Center, from which they receive no compensation. The Cardiovascular Research Foundation receives research or educational funding from Boston Scientific, Cordis, Sanofi-Aventis, and Bristol-Myers Squibb. Dr. Fahy is a paid employee of the Cardiovascular Research Foundation, and Dr. Pocock is a paid consultant of the Cardiovascular Research Foundation. No other potential conflict of interest relevant to this article was reported.
REFERENCES

1. Morice MC, Serruys PW, Sousa JE, et al. A randomized comparison of a sirolimus-eluting stent with a standard stent for coronary revascularization. N Engl J Med 2002;346:1773-80.

2. Moses JW, Leon MB, Popma JJ, et al. Sirolimus-eluting stents versus standard stents in patients with stenosis in a native coronary artery. N Engl J Med 2003;349: 1315-23.
3. Schofer J, Schluter M, Gershlick AH, et al. Sirolimus-eluting stents for treatment of patients with long atherosclerotic lesions in small coronary arteries: double-blind, randomised controlled trial (E-SIRIUS). Lancet 2003;362:1093-9.

4. Schampaert E, Cohen EA, Schluter M, et al. The Canadian study of the sirolimuseluting stent in the treatment of patients with long de novo lesions in small native coronary arteries (C-SIRIUS). J Am Coll Cardiol 2004;43:1110-5.

5. Grube E, Silber S, Hauptmann KE, et al. TAXUS I: six- and twelve-month results from a randomized, double-blind trial on a slow-release paclitaxel-eluting stent for de novo coronary lesions. Circulation 2003; 107:38-42.

6. Colombo A, Drzewiecki J, Banning A, et al. Randomized study to assess the ef- 
fectiveness of slow- and moderate-release polymer-based paclitaxel-eluting stents for coronary artery lesions. Circulation 2003; 108:788-94.

7. Stone GW, Ellis SG, Cox DA, et al. A polymer-based paclitaxel-eluting stent in patients with coronary artery disease. N Engl J Med 2004;350:221-31.

8. Stone GW, Ellis SG, Cannon L, et al. Comparison of a polymer-based paclitaxel-eluting stent with a bare metal stent in patients with complex coronary artery disease: a randomized controlled trial. JAMA 2005;294:1215-23.

9. Dawkins KD, Grube E, Guagliumi G, et al. Clinical efficacy of polymer-based paclitaxel-eluting stents in the treatment of complex, long coronary artery lesions from a multicenter, randomized trial: support for the use of drug-eluting stents in contemporary clinical practice. Circulation 2005;112:3306-13.

10. Guagliumi G, Farb A, Musumeci G, et al. Sirolimus-eluting stent implanted in human coronary artery for 16 months: pathological findings. Circulation 2003; 107:1340-1.

11. Joner M, Finn AV, Farb A, et al. Pathology of drug-eluting stents in humans: delayed healing and late thrombotic risk. J Am Coll Cardiol 2006;48:193-202.

12. Virmani R, Guagliumi G, Farb A, et al. Localized hypersensitivity and late coronary thrombosis secondary to a sirolimuseluting stent: should we be cautious? Circulation 2004;109:701-5.

13. Nebeker JR, Virmani R, Bennett CL, et al. Hypersensitivity cases associated with drug-eluting coronary stents: a review of available cases from the Research on Adverse Drug Events and Reports (RADAR) project. J Am Coll Cardiol 2006;47:175-81.
14. Ong AT, McFadden EP, Regar E, et al. Late angiographic stent thrombosis (LAST) events with drug-eluting stents. J Am Coll Cardiol 2005;45:2088-92.

15. Pfisterer M, Brunner-La Rocca HB Buser PT, et al. Late clinical events after clopidogrel discontinuation may limit the benefit of drug-eluting stents: an observational study of drug-eluting stents versus bare-metal stents. J Am Coll Cardio 2006;48:2584-91.

16. Nordmann AJ, Briel M, Bucher HC Mortality in randomized controlled trials comparing drug-eluting vs. bare metal stents in coronary artery disease: a metaanalysis. Eur Heart J 2006;27:2784-814.

17. Camenzind E, Steg G, Wijns W. Safety of drug-eluting stents: a meta-analysis of 1st generation DES programs. Presented at the European Society of Cardiology 2006 World Congress, Barcelona, September 2-6, 2006.

18. Lee MS, Jurewitz D, Aragon J, et al Strut fracture associated with sirolimuseluting stents: clinical characteristics and implications. Am J Cardiol 2006;98:Supp 8:180M. abstract.

19. Feres F, Costa JR Jr, Abizaid A. Very late thrombosis after drug-eluting stents. Catheter Cardiovasc Interv 2006;68:83 8.

20. Baierl V, Baumgartner S, Pöllinger $B$, et al. Three-year clinical follow-up after strontium-90/yttrium-90 beta-irradiation for the treatment of in-stent coronary restenosis. Am J Cardiol 2005;96:1399-403. 21. Leon MB, Teirstein PS, Moses JW, et al. Declining long-term efficacy of vascular brachytherapy for in-stent restenosis: 5-year follow-up from the gamma 1 randomized trial. Circulation 2004;110:405 abstract.
22. Pinto DS, Stone GW, Ellis SG, et al. Impact of routine angiographic follow-up on the clinical benefits of paclitaxel-eluting stents: results from the TAXUS-IV trial. J Am Coll Cardiol 2006;48:32-6.

23. Nayak AK, Kawamura A, Nesto RW, et al. Myocardial infarction as a presentation of clinical in-stent restenosis. Circ J 2006;70:1026-9.

24. Walters DL, Harding SA, Walsh CR, Wong P, Pomerantsev E, Jang IK. Acute coronary syndrome is a common clinical presentation of in-stent restenosis. Am J Cardiol 2002;89:491-4.

25. Bossi I, Klersy C, Black AJ, et al. Instent restenosis: long-term outcome and predictors of subsequent target lesion revascularization after repeat balloon angioplasty. J Am Coll Cardiol 2000;35:156976.

26. Chen MS, John JM, Chew DP, Lee DS, Ellis SG, Bhatt DL. Bare metal stent restenosis is not a benign clinical entity. Am Heart J 2006;151:1260-4.

27. Iakovou I, Schmidt T, Bonizzoni E, et al. Incidence, predictors, and outcome of thrombosis after successful implantation of drug-eluting stents. JAMA 2005;293: 2126-30.

28. Ong AT, Hoye A, Aoki J, et al. Thirtyday incidence and six-month clinical outcome of thrombotic stent occlusion after bare-metal, sirolimus, or paclitaxel stent implantation. J Am Coll Cardiol 2005;45: 947-53.

29. Cutlip D. New standard stent-thrombosis definition yields comparable event rates for DES and bare-metal stents. Presented at the Transcatheter Cardiovascular Therapeutics Symposium, Washington, DC, October 22-27, 2006.

Copyright (C) 2007 Massachusetts Medical Society. 